\title{
Kinetic and Mechanistic Studies on the Oxidation of Poly(ethylene glycol) by Ceric Sulphate in Sulphuric Acid Medium ${ }^{\dagger}$
}

\author{
S. Nagarajan, K. S. V. Srinivasan, ${ }^{\dagger \dagger}$ and K. Venkata RaO ${ }^{*}$ \\ Polymer Division, Central Leather Research Institute, Adyar, Madras 600 020, India \\ * Department of Polymer Science, University of Madras, Madras 600025 , India
}

(Received December 20, 1993)

\begin{abstract}
The kinetics of oxidation of a macromolecule, poly(ethylene glycol) [PEG] by ceric sulphate in sulphuric acid medium has been studied by means of UV-visible spectrophotometer with a view to find out any difference in oxidative behavior of monomeric and polymeric analogue. The observed difference in rates of oxidation has been explained in terms of cage formation. The oxidation of PEG proceeded without the formation of a stable intermediate complex. The order with respect to the concentrations of PEG and ceric sulphate has been found to be one and the overall order is two. The effects of acid concentration, sulphate ion concentration, ionic strength and temperature on the rate of the oxidation reaction have been studied and suitable explanations have been given. The thermodynamic parameters for the oxidation reaction have also been presented. Based on the experimental results, a suitable kinetic expression and a plausible mechanism have been proposed for the oxidation reaction.
\end{abstract}

KEY WORDS Oxidation / Poly(ethylene glycol) / Ceric sulphate / Kinetics / Mechanism / Molecular Weight /

The use of ceric ion as an oxidant is of considerable importance and interest to many fields of chemistry. Oxidation studies of several substrates by $\mathrm{Ce}$ (IV) were reported in literature. ${ }^{1-5}$ Ceric ion is also used as an initiator either as such or in combination with reducing agents for vinyl polymerization, ${ }^{6-10}$ graft copolymerization $^{11,12}$ as well as for block copolymerization. ${ }^{13,14}$ According to the theory of oxidation of alcohols, ${ }^{15}$ the rate determining step for the production of a free radical on the alcohol substrate is the unimolecular disproportionation of a coordination complex, $\mathrm{C}$, to yield a free radical, a cerous ion and a proton.

$$
\underset{\mathrm{I}}{\mathrm{OH}}-\mathrm{H}+\mathrm{Ce}(\mathrm{IV}) \stackrel{K}{=}=\mathrm{C}
$$

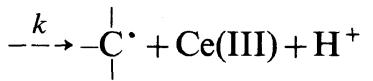

If the alcohol is 1,2-diol, the $\mathrm{C}-\mathrm{C}$ bond between the hydroxyls cleaves to yield an aldehyde or ketone and a free radical.

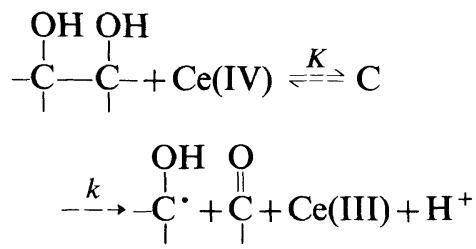

The fate of the free radical in both cases is supposedly fast oxidation by another ceric ion.

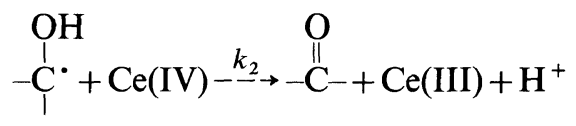

\footnotetext{
${ }^{+}$Presented partly at the XXII IULTCS Congress, Porto Alegre, Brazil, November 1993.

${ }^{\dagger \dagger}$ To whom all correspondence should be addressed.
} 
The kinetic studies on oxidation of substrates by $\mathrm{Ce}$ (IV) has been confined to simple molecules. Prakash et al. ${ }^{16}$ studied the oxidation behaviors of 1,3-, 1,4-, 1,5-, and 1,6-diols by $\mathrm{Ce}(\mathrm{IV})$ in aqueous perchloric acid medium and reported that the rate of oxidation of diols increases with the increase in the relative distance between the two hydroxyl groups. Storey et al. ${ }^{17}$ studied the oxidation of poly(vinyl alcohol) by $\mathrm{Ce}(\mathrm{IV})$ and inferred that the 1,2-diols, which are inherent defects in poly(vinyl alcohol), are the most reactive sites for oxidation.

This paper deals with some interesting kinetic and mechanistic aspects on the ceric ion oxidation of poly(ethylene glycol) [PEG], an $\alpha, \omega$-diol, with varying molecular weight range (200 to 9000) and ethylene glycol (EG). The kinetic and thermodynamic parameters have been evaluated.

\section{EXPERIMENTAL}

\section{Reagents}

PEG (s.d. chem., India) was purified by first dissolving in benzene and then passing through a column filled with activated alumina in a stream of nitrogen. It was then lyophilized and characterized for high molecular weight homogeneity, as shown by the value $\bar{M}_{w} / \bar{M}_{n}=$ 1.15 .

Stock solutions of Ce(IV) were prepared by dissolving ceric sulphate (CS, s.d. chem., India) in standard sulphuric acid. These solutions were then titrated against standard ammonium ferrous sulphate for their $\mathrm{Ce}(\mathrm{IV})$ content and were double checked spectrophotometrically.

All the other reagents used were of AR grade. Triple distilled water was used for the preparation of all the solutions.

\section{Kinetic Measurements}

The rate of the reaction was determined by following the disappearance of Ce(IV) with time by means of optical density change using a Beckman Model 26 recording spectropho- tometer at $304 \mathrm{~nm}$. At this wavelength, all the other reactants and products had negligible absorption. All the kinetic experiments were run with the organic substrate in excess so that the reactions would be pseudo first-order with respect to $\mathrm{Ce}(\mathrm{IV})$.

After thermostating the reactant solutions at $26^{\circ} \mathrm{C}$ for $20 \mathrm{~min}$ in a constant temperature bath, the reaction was initiated by adding the oxidant, CS. A portion of the reaction mixture was transferred to a $1 \mathrm{~cm}$ UV quartz cell and the recording of optical density with time was started. The reaction temperature in the spectrophotometer cell was maintained constant by circulating water from the bath through a thermostatable cell jacket. The temperatures reported are the mean of the temperatures measured at the inlet and outlet of the cell jacket. Temperature fluctuations were less than $\pm 0.05^{\circ} \mathrm{C}$ and the reaction temperatures were estimated to be accurate to $\pm 0.1^{\circ} \mathrm{C}$

The spectrophotometric method was found to give results equivalent to titrimetric procedure as checked for a set of experiments.

Pseudo first-order rate constants were calculated from $t_{1 / 2}$ values obtained from plots of the logarithm of optical density change versus time using the relationship,

$$
k=\frac{0.693}{t_{1 / 2}} \text { time }^{-1}
$$

The rate constants were determined by varying the concentrations of $\mathrm{Ce}^{4+}, \mathrm{PEG}, \mathrm{H}^{+}$, $\mathrm{SO}_{4}^{2-}$, and molecular weight of PEG.

CS solutions were found to be stable in aqueous sulphuric acid medium. The stabilities of CS solutions were proved by Willard and Young ${ }^{18}$ who kept a $0.1 \mathrm{M}$ solution of CS (in $1 \mathrm{M}$ sulphuric acid) for nearly an year without any change in titre value with ammonium ferrous sulphate.

Polymerization of Acrylonitrile

Aliquots of different concentrations of CS 
and PEG were mixed with a solution of acrylonitrile monomer. Polymerization of acrylonitrile was indicated by the appearance of turbidity. The monomer, however, did not polymerize when it was added to solutions of CS and PEG taken separately.

\section{RESULTS AND DISCUSSION}

\section{Ce(IV)-PEG Reaction in Sulphuric Acid} Medium

The oxidation of PEG by CS was studied at $26^{\circ} \mathrm{C}$. Pseudo first-order and second-order kinetic plots showed an excellent linearity. The rate of oxidation depends directly on the concentrations of CS and PEG. At constant $\mathrm{pH}$ and in the presence of excess PEG, the reaction is first-order with respect to the ceric ion concentration. The plot of $\log k$ against $\log$ [PEG] gave a straight line with a slope of unity (Figure 1). Hence the reaction is first order with respect to the concentration of PEG whereas the overall order of this reaction is two. This was verified by plotting $\log \{(a-x) /(b-x)\}$ against time (Figure 2) where $a=[\mathrm{CS}]=$

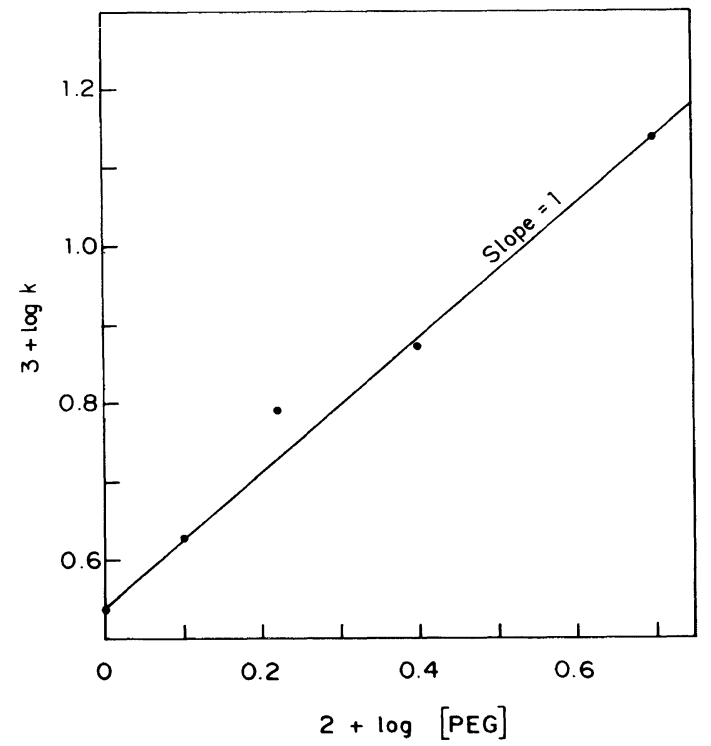

Figure 1. Plot of $\log k$ against $\log [\mathrm{PEG} 400]$ : $[\mathrm{Ce}(\mathrm{IV})]=1.5 \times 10^{-4} \mathrm{M} ; \quad\left[\mathrm{H}^{+}\right]=0.1 \mathrm{M} ; \mu=1.05 \mathrm{M}$ temp $=299 \mathrm{~K}$.
$0.774 \times 10^{-4} \mathrm{M}, b=[\mathrm{PEG}]=1.5 \times 10^{-3} \mathrm{M}$, $\left[\mathrm{H}^{+}\right]=0.1 \mathrm{M}$, and $\mu=1.05 \mathrm{M}$ at $26^{\circ} \mathrm{C}$.

The absence of polynuclear complexes in CS solutions, demonstrated by Hardwick and Robertson ${ }^{19}$ was also observed in this study by the constancy of $k$ with increasing concentration of $\mathrm{Ce}$ (IV) (Table I).

The polymerization of acrylonitrile by $\mathrm{Ce}(\mathrm{IV})-\mathrm{PEG}$ system indicates that free radical species were formed during the reaction. This macromolecular oxidation proceeding via a radical intermediate was used for the selective synthesis of block copolymers ${ }^{13,14,20}$ by us.

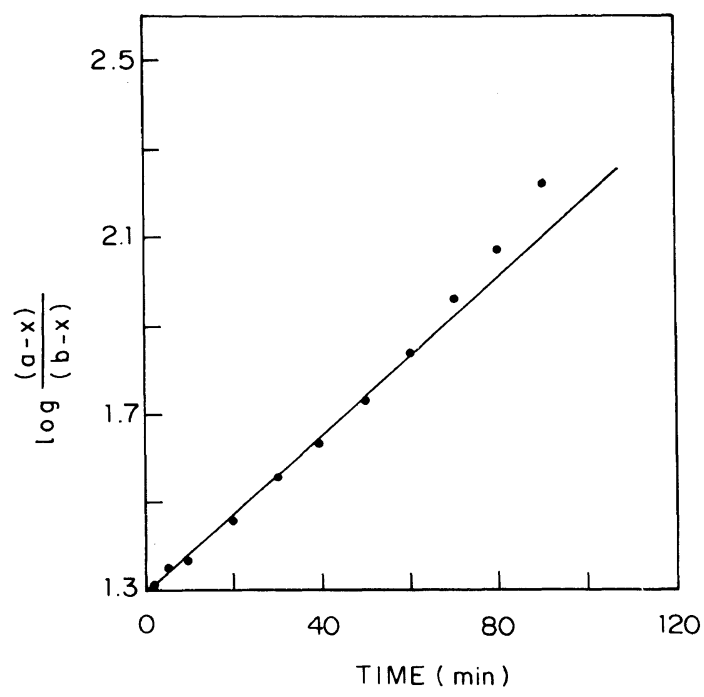

Figure 2. Verification of overall order: $[\mathrm{Ce}(\mathrm{IV})]=$ $0.774 \times 10^{-4} \mathrm{M} ;\left[\right.$ PEG 400] $=1.5 \times 10^{-3} \mathrm{M} ;\left[\mathrm{H}^{+}\right]=0.1 \mathrm{M}$; $\mu=1.05 \mathrm{M}$; temp $=299 \mathrm{~K}$.

Table I. Effect of ceric ion concentration on the pseudo first-order rate constant

[PEG 400] $=3 \times 10^{-3} \mathrm{M} ;\left[\mathrm{H}^{+}\right]=0.05 \mathrm{M} ; \mu=1.05 \mathrm{M}$; temp $=299 \mathrm{~K}$.

\begin{tabular}{cccc}
\hline $\mathrm{Ce}(\mathrm{IV})] \times 10^{4}$ & & $\frac{t_{1 / 2}}{k}$ & \\
$\mathrm{mol1}^{-1}$ & & $\mathrm{~min}^{-1}$ & $\mathrm{~s}^{-1}$ \\
\hline 1.0 & 85 & 1.359 \\
1.5 & 86 & 1.343 \\
2.0 & 85 & 1.359 \\
2.5 & 79 & 1.462 \\
3.0 & 81 & 1.426 \\
\hline
\end{tabular}




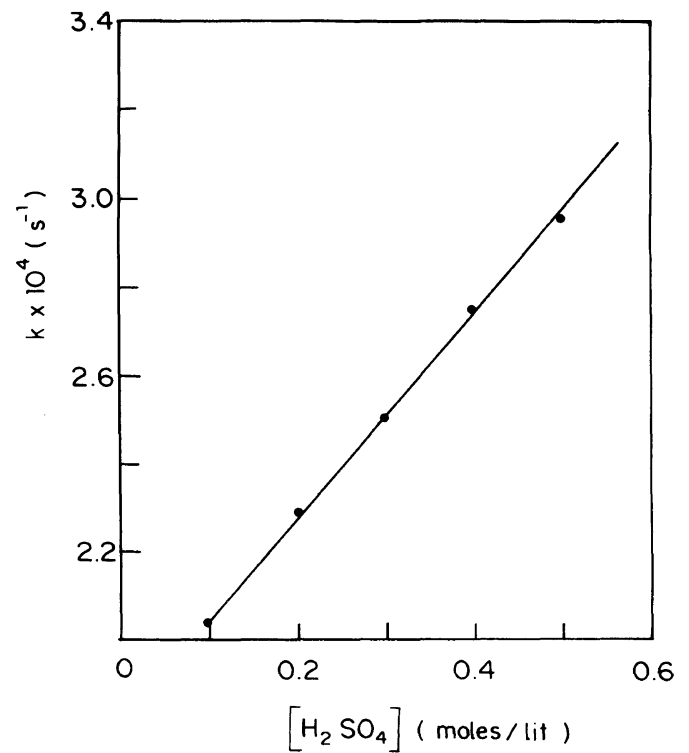

Figure 3. Plot of $k$ against $\left[\mathrm{H}_{2} \mathrm{SO}_{4}\right]$ : $[\mathrm{Ce}(\mathrm{IV})]=1 \times 10^{-4}$ $\mathrm{M} ;\left[\right.$ PEG 400] $=8 \times 10^{-3} \mathrm{M} ; \mu=1.05 \mathrm{M}$; temp $=299 \mathrm{~K}$.

Table II. Effect of sulphuric acid concentration on the pseudo first-order rate constant $299 \mathrm{~K}$.

$[\mathrm{PEG}] \doteq 2 \times 10^{-3} \mathrm{M} ;[\mathrm{Ce}(\mathrm{IV})]=1.5 \times 10^{-4} \mathrm{M}$; temp $=$

\begin{tabular}{ccc}
\hline $\left.\mathrm{H}_{2} \mathrm{SO}_{4}\right]$ & \multicolumn{1}{c}{$t_{1 / 2}$} & $k \times 10^{4}$ \\
\cline { 2 - 3 } $\mathrm{mol1}^{-1}$ & $\min ^{-1}$ & $\mathrm{~s}^{-1}$ \\
\hline 0.10 & 47 & 2.458 \\
0.15 & 51 & 2.265 \\
0.20 & 55 & 2.100 \\
0.30 & 80 & 1.650 \\
0.40 & 104 & 1.313 \\
0.50 & & 1.111 \\
\hline
\end{tabular}

Effect of $\left[\mathrm{H}_{2} \mathrm{SO}_{4}\right]$ and Ionic Strength

Keeping the ionic strength a constant $(\mu=1.05 \mathrm{M})$, the effect of $\left[\mathrm{H}_{2} \mathrm{SO}_{4}\right]$ was studied in the range $0.1-0.6 \mathrm{M}$ with solutions containing $8 \times 10^{-3} \mathrm{M}$ PEG and $1 \times 10^{-4} \mathrm{M}$ $\mathrm{CS}$ at $26^{\circ} \mathrm{C}$. The plot of the rate constant against $\left[\mathrm{H}_{2} \mathrm{SO}_{4}\right]$ (Figure 3 ) showed a direct dependence of the rate on the concentration of the acid. But, when the ionic strength was not maintained constant, the rate decreased directly with the increase of $\left[\mathrm{H}_{2} \mathrm{SO}_{4}\right]$ which

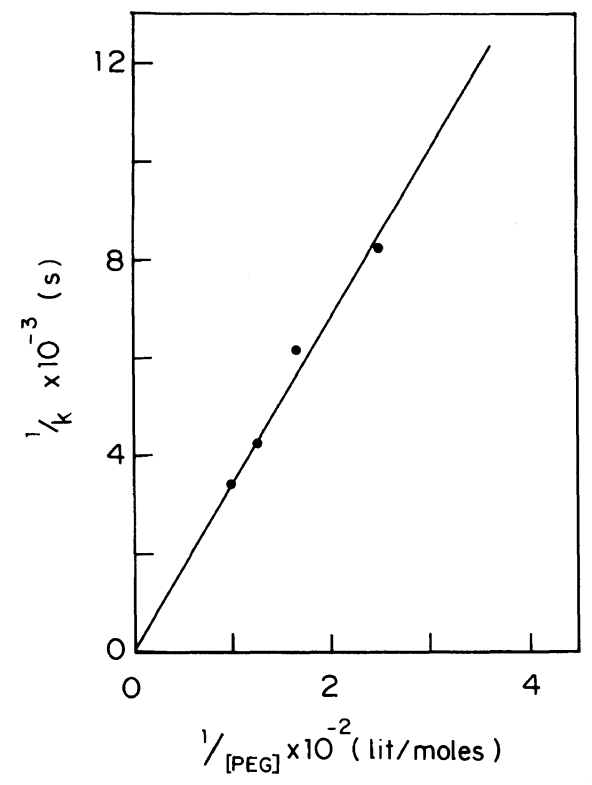

Figure 4. Plot of $1 / k$ against $1 /[\mathrm{PEG} 400]$. Experimental conditions same as in Figure 2.

was studied using $2 \times 10^{-3} \mathrm{M}$ PEG and $1.5 \times 10^{-4} \mathrm{M}$ CS with the acid concentration ranging from 0.1 to $0.6 \mathrm{M}$. These data are contained in Table II.

\section{Search for Complex Formation}

The plot of $1 / k$ versus $1 /[$ PEG] (Figure 4) was a straight line passing through the origin. Further, from the absorption spectra of CS and CS-PEG mixture (Figure 5), it can be seen that after the addition of PEG there is no shift in the absorption maxima of $\mathrm{Ce}^{4+}$. Both these facts indicate that there is no complex formation between $\mathrm{Ce}^{4+}$ and PEG during the oxidation. On the other hand, the ceric ion oxidation of ethylene glycol proceeded with the formation of an intermediate complex. ${ }^{21}$ This can be explained as follows:

Ethylene glycol, being an 1,2-diol forms a chelate complex favorably. ${ }^{21}$ In the case of PEG, the two alcoholic groups are far away from each other. As the distance between two alcoholic groups increases, the formation of a stable intermediate complex seems to be less favored. A similar explanation was put 
forward by Prakash et al. ${ }^{16}$

Effect of $\left[\mathrm{SO}_{4}^{2-}\right]$ Ions on $\mathrm{Ce}(\mathrm{IV})-\mathrm{PEG}$ Reaction

The effect of $\left[\mathrm{SO}_{4}^{2-}\right]$ ions was studied by adding $\mathrm{Na}_{2} \mathrm{SO}_{4}$ using $1.5 \times 10^{-4} \mathrm{M} \mathrm{CS}$ and $2.0 \times 10^{-3} \mathrm{M}$ PEG at $50^{\circ} \mathrm{C}$ maintaining the acid concentration at $0.1 \mathrm{M}$. The addition of $\mathrm{Na}_{2} \mathrm{SO}_{4}$ caused a large retardation in the oxidation of PEG by CS. These data are contained in Table III.

\section{Effect of Temperature}

Using a mixture of $2 \times 10^{-3} \mathrm{M}$ PEG, $1.5 \times 10^{-4} \mathrm{M} \mathrm{CS}$, and $0.1 \mathrm{M} \mathrm{H}_{2} \mathrm{SO}_{4}$, the first order rate constants were determined at different temperatures and the thermodynamic parameters were then calculated. These data

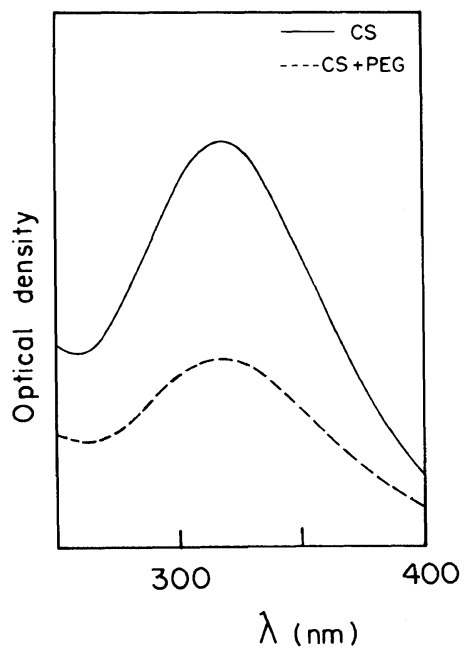

Figure 5. Absorption spectra of ceric sulphate before $(-)$ and after (--) mixing with PEG 400. are given in Table IV. The relatively lower $E_{\mathrm{a}}$ values indicate the facile nature of the reaction between $\mathrm{Ce}^{4+}$ and PEG. Further as the molecular weight of PEG increases, $\Delta S^{\#}$ becomes less negative indicating a decreasing tendency to form a stable complex.

\section{Effect of Molecular Weight of PEG}

The oxidations of PEG of various molecular weights were studied at $26^{\circ} \mathrm{C}$. The oxidation of EG was also studied under identical conditions for comparison purposes using $3.33 \times 10^{-3} \mathrm{M} \mathrm{EG} / \mathrm{PEG}, 0.667 \times 10^{-4} \mathrm{M} \mathrm{CS}$, $0.33 \mathrm{M} \mathrm{H}_{2} \mathrm{SO}_{4}$ keeping $\mu$ at $1.05 \mathrm{M}$. It was found that the rate increased with the increase in the molecular weight of PEG. The plot of rate constant versus molecular weight of PEG was found to be linear (Figure 6).

As the molecular weight of PEG increases, the viscosity of the medium should increase, retarding the diffusion of the oxidant to reach the substrate. Hence, one would expect a lower rate with increase in the molecular weight of

Table III. Effect of sulphate ion concentration on the pseudo first-order rate constant

$\left[\right.$ PEG 400] $=2 \times 10^{-3} \mathrm{M}$; $[\mathrm{Ce}(\mathrm{IV})]=1.5 \times 10^{-4} \mathrm{M}$; $\left[\mathrm{H}^{+}\right]=0.1 \mathrm{M}$; temp $=323 \mathrm{~K}$.

\begin{tabular}{|c|c|c|}
\hline$\left[\mathrm{SO}_{4}^{2-}\right] \times 10^{2}$ & $t_{1 / 2}$ & $k \times 10^{4}$ \\
\hline $\mathrm{moll}^{-1}$ & $\min ^{-1}$ & $\mathrm{~s}^{-1}$ \\
\hline 0.000 & 80 & 1.4438 \\
\hline 0.704 & 86 & 1.3430 \\
\hline 1.408 & 92 & 1.2554 \\
\hline 2.112 & 100 & 1.1550 \\
\hline 2.816 & 108 & 1.0694 \\
\hline
\end{tabular}

Table IV. Thermodynamic parameters

$[\mathrm{PEG}]=2 \times 10^{-3} \mathrm{M} ;[\mathrm{Ce}(\mathrm{IV})]=1.5 \times 10^{-4} \mathrm{M} ;\left[\mathrm{H}^{+}\right]=0.1 \mathrm{M} ; \mu=1.05 \mathrm{M}$.

\begin{tabular}{|c|c|c|c|c|}
\hline \multirow{2}{*}{ Substrate } & $E_{\mathrm{a}}$ & $\Delta G^{\#}$ & $\Delta H^{\#}$ & $\Delta S^{\sharp}$ \\
\hline & $\mathrm{K} \mathrm{cal}^{-1} \mathrm{~mol}^{-1}$ & $\mathrm{~K} \mathrm{cal}^{-1}$ & $\mathrm{~K} \mathrm{cal}^{-1}$ & cal deg ${ }^{-1} \mathrm{~mol}^{-1}$ \\
\hline PEG 400 & 10.49 & 24.07 & 9.86 & -47.22 \\
\hline PEG 4000 & 9.81 & 21.84 & 9.22 & -43.04 \\
\hline PEG 6000 & 8.58 & 20.45 & 8.00 & -42.50 \\
\hline
\end{tabular}




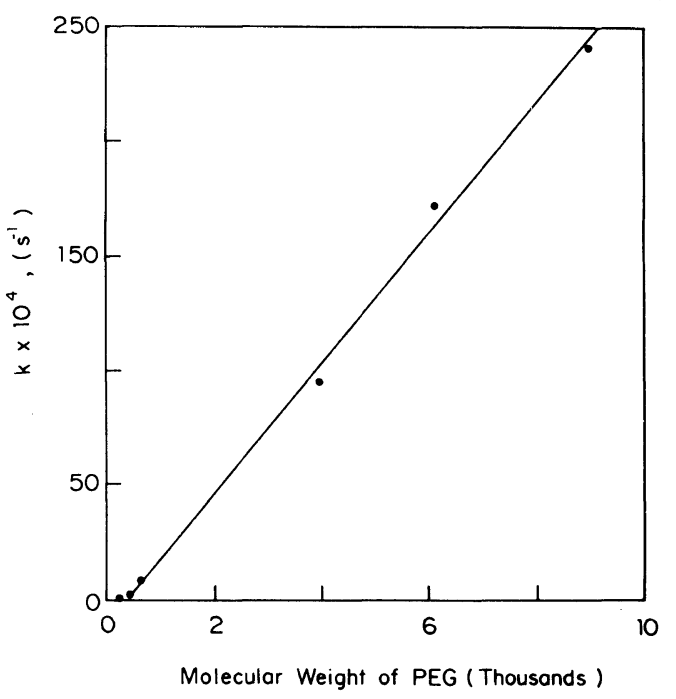

Figure 6. Plot of $k$ against molecular weight of PEG: $[\mathrm{EG} / \mathrm{PEG}]=3.33 \times 10^{-3} \mathrm{M} ; \quad[\mathrm{Ce}(\mathrm{IV})]=0.667 \times 10^{-4} \mathrm{M}$; $\left[\mathrm{H}^{+}\right]=0.33 \mathrm{M} ; \mu=1.05 \mathrm{M}$; temp $=299 \mathrm{~K}$.

the substrate. But our observation is contrary to the expectation which could be explained as follows:

In aqueous solutions, PEG can exist in the following ways:

a) It may be linear and completely free from each other.

b) It may be linear and associated.

c) It may be highly coiled with $\mathrm{OH}$ groups inside or outside the cages.

d) There may be formation of more polar (due to $\mathrm{OH}$ groups) and less polar (due to ether linkages) regions.

e) $\mathrm{Ce}(\mathrm{IV})$ may accommodate in polymer free regions, less polar regions, more polar regions or within the cages.

The rate of oxidation of PEG by CS depends on the availability or the resting time of $\mathrm{Ce}$ (IV) in the immediate vicinity of $\mathrm{OH}$ groups. In the case of low molecular weight PEG, contribution of (c) and (d) will be less which are likely to play an important role in this oxidation reaction.

A system of coils with $\mathrm{Ce}(\mathrm{IV})$ and $\mathrm{OH}$ groups will be more stable within the cages. This also provides more opportunity for $\mathrm{Ce}(\mathrm{IV})$ to meet and then oxidize $\mathrm{OH}$ groups. This type of contribution to rate will be less in low molecular weight PEG, and thus lower the rate.

Reactive Ce(IV) Species in the Oxidation ${ }^{19}$

Several complexes of $\mathrm{Ce}(\mathrm{IV})$ can exist in aqueous sulphuric acid solution of CS depending on the concentrations of CS and sulphuric acid such as,

$$
\begin{aligned}
& \left\{\mathrm{Ce}\left(\mathrm{SO}_{4}\right)\right\}^{2+}, \quad\left\{\mathrm{Ce}(\mathrm{OH}) \mathrm{SO}_{4}\right\}^{+}, \\
& \left\{\mathrm{Ce}\left(\mathrm{SO}_{4}\right)_{2}\right\}, \quad\left\{\mathrm{Ce}\left(\mathrm{SO}_{4}\right)_{3}\right\}^{2-}, \\
& \left\{\mathrm{HCe}\left(\mathrm{SO}_{4}\right)_{3}\right\}^{-}, \quad\left\{\mathrm{H}_{2} \mathrm{Ce}\left(\mathrm{SO}_{4}\right)_{4}\right\}^{2-}, \\
& \text { and }\left\{\mathrm{Ce}\left(\mathrm{SO}_{4}\right)_{4}\right\}^{4-}
\end{aligned}
$$

The choice of the right species is difficult to speculate. Our observation showed that the rate of oxidation of PEG by CS decreased on the addition of sulphuric acid point to the fact that the reactive species should be the covalently bonded $\mathrm{CS}, \mathrm{Ce}\left(\mathrm{SO}_{4}\right)_{2}$. This is also supported by the stability of CS and that the addition of PEG to CS does not change its color (indicating the presence of covalent bonding between $\mathrm{Ce}^{4+}$ and $\mathrm{SO}_{4}^{2-}$ ).

\section{Probable Mechanism of the Reaction}

On the basis of our observations, we assumed that CS and PEG react to form a transition state which then decomposes to produce a free radical, a cerous ion and a proton. The free radical then picks up one more $\mathrm{Ce}^{4+}$ and quickly produces the products of the reaction.

$$
\begin{aligned}
& \mathrm{H}\left(\mathrm{OCH}_{2} \mathrm{CH}_{2}\right)_{m} \mathrm{OCH}_{2} \mathrm{CH}_{2} \mathrm{OH}+\mathrm{Ce}^{4+} \\
& \text { PEG } \\
& \underset{\text { Slow }}{\stackrel{k}{\rightarrow}} \underset{\text { Transition state }}{\mathrm{PEG}} . \mathrm{Ce}\left(\mathrm{SO}_{4}\right)_{2} \\
& \rightarrow \mathrm{H}\left(\mathrm{OCH}_{2} \mathrm{CH}_{2}\right)_{m} \mathrm{OCH}_{2} \dot{\mathrm{C}} \mathrm{HOH} \\
& +\mathrm{Ce}^{3+}+\mathrm{H}^{+} \\
& \underset{\text { fast }}{\stackrel{\mathrm{Ce}^{4+}}{\rightarrow}} \underset{\text { Long chain aldehyde }}{\mathrm{H}}\left(\mathrm{OCH}_{2} \mathrm{CH}_{2}\right)_{m} \mathrm{OCH}_{2} \mathrm{CHO} \\
& +\mathrm{Ce}^{3+}+\mathrm{H}^{+}
\end{aligned}
$$

The retarding action of $\mathrm{H}_{2} \mathrm{SO}_{4}\left(--\rightarrow \mathrm{H}^{+}+\right.$ $\mathrm{HSO}_{4}^{-}$) and sulphate ions might be due to 
the removal of $\mathrm{Ce}\left(\mathrm{SO}_{4}\right)_{2}$ by the reactions, ${ }^{22}$

$$
\begin{aligned}
\mathrm{Ce}\left(\mathrm{SO}_{4}\right)_{2}+\mathrm{HSO}_{4}^{-} & ==\mathrm{HCe}\left(\mathrm{SO}_{4}\right)_{3}^{-} \\
\mathrm{Ce}\left(\mathrm{SO}_{4}\right)_{2}+\mathrm{SO}_{4}^{2-} & ==\rightleftharpoons \mathrm{Ce}\left(\mathrm{SO}_{4}\right)_{3}^{2-}
\end{aligned}
$$

while the accelerating effect of $\mathrm{H}^{+}$ions at constant ionic strength might be due to the reactions,

$$
\begin{gathered}
\mathrm{Ce}\left(\mathrm{SO}_{4}\right)_{2} \rightleftharpoons \mathrm{Ce}\left(\mathrm{SO}_{4}\right)^{2+}+\mathrm{SO}_{4}^{2-} \\
\mathrm{Ce}\left(\mathrm{SO}_{4}\right)^{2+}+\mathrm{H}_{2} \mathrm{O} \rightleftharpoons=\mathrm{Ce}(\mathrm{OH}) \mathrm{SO}_{4}^{+}+\mathrm{H}^{+}
\end{gathered}
$$

Now the rate of the reaction is given by,

$$
-\mathrm{d}[\mathrm{Ce}(\mathrm{IV})] / \mathrm{d} t=K^{\prime \prime}\left[\mathrm{Ce}\left(\mathrm{SO}_{4}\right)_{2}\right][\mathrm{PEG}]
$$

which is first order with respect to both the reagents and the overall order is two. Hence, the bimolecular rate constant can be calculated by,

$$
K^{\prime \prime}=\frac{2.303}{t(b-a)} \log \frac{a(b-x)}{b(a-x)}
$$

where $b>a$ and $x$ is the quantity of $\mathrm{Ce}$ (IV) disappearing in the time interval, $t$. From eq 3 ,

$$
\left[\mathrm{Ce}\left(\mathrm{SO}_{4}\right)_{2}\right]=\left[\mathrm{HCe}\left(\mathrm{SO}_{4}\right)_{3}\right] / \mathrm{K}\left[\mathrm{HSO}_{4}^{-}\right]
$$

Substituting in eq 7 , we get,

$$
\begin{aligned}
& -\mathrm{d}[\mathrm{Ce}(\mathrm{IV})] / \mathrm{d} t \\
& \quad=K^{\prime \prime}\left\{\mathrm{HCe}\left(\mathrm{SO}_{4}\right)_{3}^{-}\right][\mathrm{PEG}] / K\left[\mathrm{HSO}_{4}^{-}\right]
\end{aligned}
$$

Assuming $\mathrm{HCe}\left(\mathrm{SO}_{4}\right)^{3-}$ is proportional to $\mathrm{Ce}(\mathrm{IV})$ and $\mathrm{HSO}_{4}^{-}$is proportional to $\mathrm{H}_{2} \mathrm{SO}_{4}$, we get,

$$
-\mathrm{d}[\mathrm{Ce}(\mathrm{IV})] / \mathrm{d} t=K^{\prime}[\mathrm{PEG}][\mathrm{Ce}(\mathrm{IV})] /\left[\mathrm{H}_{2} \mathrm{SO}_{4}\right]
$$

Thus the dependence of the rate of oxidation reaction on the concentrations of PEG, $\mathrm{Ce}$ (IV) and $\mathrm{H}_{2} \mathrm{SO}_{4}$ can be explained.

Acknowledgements. The authors thank Dr. M. Palanichamy, Department of Chemistry,
College of Engineering, Anna University for his useful discussion. One of the authors (S.N.) gratefully acknowledges the University Grants Commission (U.G.C.) and the Council of Scientific and Industrial Research (C.S.I.R.) in India for the financial assistance.

\section{REFERENCES}

1. B. U. Nair, T. Ramasami, and D. Ramaswamy, Int. J. Chem. Kinet., 19, 277 (1987).

2. M. P. Alvarez-Macho and F. Mata-Perez, React. Kinet. Catal. Lett., 46, 167 (1992).

3. A. S. Sarac, Int. J. Chem. Kinet., 17, 1333 (1985).

4. W. S. Trahanovsky, L. B. Young, and G. L. Brown, J. Org. Chem., 32(12), 3865 (1967).

5. S. B. Hanna and A. S. Sarac, J. Org. Chem., 42(12), 2063 (1977).

6. M. L. Leza and G. M. Guzman, Eur. Polym. J., 27, 445 (1991).

7. J. Saldick, J. Polym. Sci., 19, 73 (1956).

8. G. Mino and S. Kaizerman, J. Polym. Sci., 31, 242 (1958).

9. G. S. Misra and B. D. Arya, J. Polym. Sci., 22, 3563 (1984).

10. M. D. Fernandez and G. M. Guzman, J. Polym. Sci., 27, 3703 (1989).

11. D. Sudhakar, K. S. V. Srinivasan, and M. Santappa, J. Appl. Polym. Sci., 23, 2923 (1973).

12. M. D. Fernandez, I. Casinos, and G. M. Guzman, J. Appl. Polym. Sci., 41, 2221 (1990).

13. S. Nagarajan and K. S. V. Srinivasan, Eur. Polym. J., 30(1), 113 (1994).

14. S. Nagarajan and K. S. V. Srinivasan, J. Macromol. Sci.-Pure \& Appl. Chem., A30 (Suppl. 5), 397 (1993).

15. F. R. Duke and A. A. Forist, J. Am. Chem. Soc., 71, 2790 (1949).

16. A. Prakash, R. N. Mehrotra, and R. C. Kapoor, J. Chem. Soc., Dalton Trans., 2, 205 (1979).

17. R. F. Storey and L. J. Goff, J. Polym. Sci., 27, 3837 (1989).

18. H. H. Willard and P. Young, J. Am. Chem. Soc., 50, $1322,1334,1368,1372$, and 1379 (1928), 51, 139 and 149 (1929).

19. T. J. Hardwick and E. Robertson, Can. J. Chem., 29, 828 (1951).

20. S. Nagarajan, S. Sudhakar, and K. S. V. Srinivasan, Colloid \& Polym. Sci., in press.

21. A. A. Katai, V. K. Kulshrestha, and R. H. Marchessault, J. Polym. Sci., C, 2, 403 (1963).

22. W. H. Richardson, "Oxidation in Organic Chemistry," Part A, K. B. Wiberg, Ed., Academic Press, New York, N.Y., 1965, p 245. 